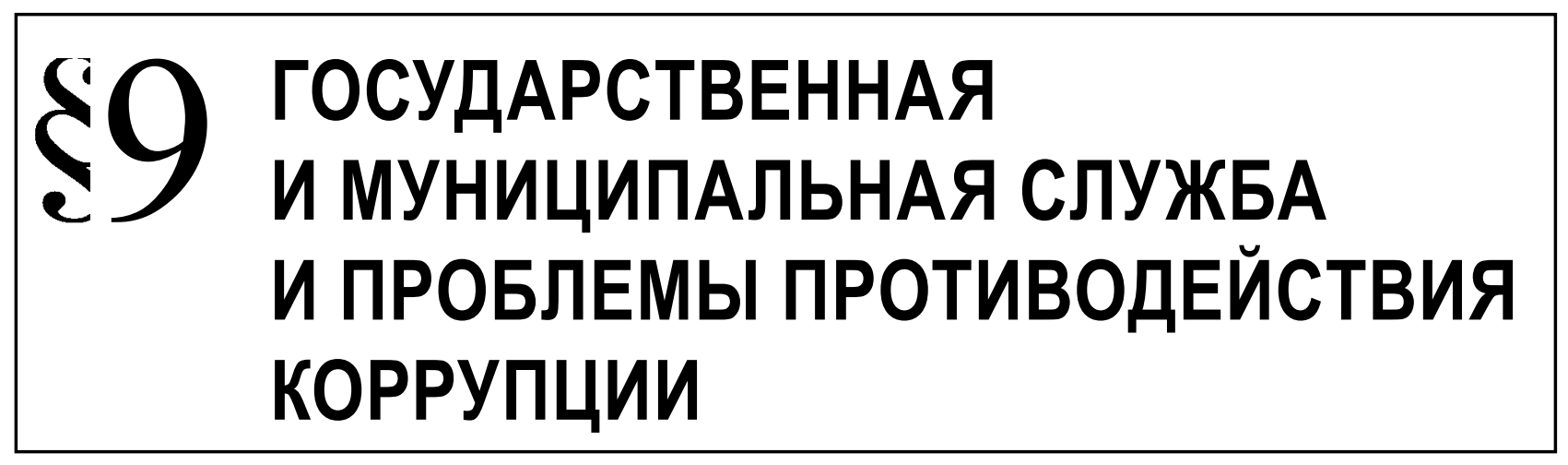

Лаврентьева О.О.

\title{
ПРИНЦИПЫ ПРОТИВОДЕЙСТВИЯ КОРРУПЦИОННЫМ ПРАВОНАРУШЕНИЯМ В СИСТЕМЕ ГОСУДАРСТВЕННОЙ ГРАЖДАНСКОЙ СЛУЖБЫ
}

Аннотация. Предметом статьи являются проблемы правового и организационного характера, связанные с противодействием коррупционным правонарушениям в системе государственной гражданской службы. Объектом статьи является круг общественных отношений связанных с противодействием коррупционным правонарушениям в системе государственной гражданской службы. Авторами подробно рассматриваются составляющие механизма административно-правового регулирования противодействия коррупции на основании чего формулируются предложения по повышению эффективности административно-правовых средств противодействия коррупции. Основное внимание в статье уделяется разработки критериев эффективности противодействия коррупционным правонарушениям. Методологическую основу статьи составили современные достижения теории познания. В процессе исследования применялись общефилософский, теоретический, общефилософские методы (диалектика, системный метод, анализ, синтез, аналогия, дедукция, наблюдение, моделирование), традиционно правовые методы (формально-логический), а также методы, используемые в конкретно-социологических исследованиях (статистические, экспертные оценки и др.). Основной вывод, который сделан по итогам исследования административных принципов противодействия коррупции в системе государственной гражданской службы, является то, что обозначенное направление реализуемой в сфере публичного управления не достаточно эффрективно. В этой связи в настоящее время необходимо развивать правовую основу деятельности органов государственной власти и управления по противодействию коррупции. Основным вкладом, который сделан авторами в настоящей статье это обращение внимание на обозначенную проблему. Новизна статьи заключается в разработке инструментария противодействия коррупции в системе государственной службы.

Ключевые слова: коррупция, правонарушение, ущерб, служба, чиновник, взятка, противодействие, борьба, система, средство.

Review. The subject of the research is the range of legal and organizational problems of combating corruption in the system of civil service. The object of the research is the range of public relations connected with combating corruption in the system of civil service. The author considers the components of the mechanism of administrative-legal regulation of combating corruption and formulates the proposals about the increase of the efficiency of administrativelegal means of combating corruption. The main attention is paid to the development of the criteria of efficiency of combating corruption. The methodology of the research is based on the recent achievements of epistemology. The author applies the general philosophical and theoretical methods (dialectics, the systems method, analysis, synthesis, analogy, deduction, observation, modeling), the traditional legal methods (formal-logical), and the methods of special sociological research (statistical methods, expert assessment, etc.). The author concludes that combating corruption in the system of civil service is not efficient enough. Therefore, it is necessary to develop the legal base for the activities of public authorities and public administration aimed at combating corruption. The main contribution of the author is the attention to this problem. The novelty of the research lies in the development of instruments for combating corruption in the system of public service.

Keywords: struggle, combating, bribe, official, service, damage, offence, corruption, system, means. 
$\mathrm{B}$ системе исходных начал противодействия коррупции в системе государственной службы важное место принадлежит принципам, на которых должна строиться и осуществляться деятельность по предупреждению и пресечению коррупции. В связи с этим в целях дальнейшего совершенствования мероприятий, направленных на противодействие коррупции в сфере публичного управления, представляется необходимым уточнение общей характеристики принципов данного вида деятельности, а также определение той роли, которую они играют в сфере предупреждения и пресечения коррупции.

Принцип - это идея. Правовые принципы определяются как основополагающие идеи, закрепленные в законе. Они приобретают значение императивных требований, конкретных правил и обязывают правоприменителя к определенному поведению или устанавливают определенные запреты. Учитывая значение правовых принципов, можно сказать, что качество законов и эффективность правового регулирования, а применительно к теме настоящей работы, предупреждение и пресечение коррупции в сфере государственного управлении, во многом зависит от того, как в законодательстве сформулированы и раскрыты такие принципы [1] .

Следует отметить, что в настоящее время специальные принципы противодействия коррупции в сфере публичного управления в законодательстве не содержатся, данное обстоятельство обусловлено тем в что в настоящее время до сих пор не принят Федеральный закон «0 противодействии коррупции», именно в данном нормативном правовом акте и должны содержаться принципы, на которых непосредственно должна строиться деятельность уполномоченных субъектов, направленная на противодействии коррупции в Российской Федерации.

Анализ международных актов, направленных на противодействии коррупции в государственном аппарате, а также юридической литературы позволил выявить ряд принципов, на которых должна осуществляться деятельность по противодействию коррупции.

Так, В.Н. Лопатин выделяет следующие принципы:

- партнерство субъектов антикоррупционной политики;

- приоритет мер предупреждения коррупции и нравственных начал борьбы против коррупции;

- недопустимость установления антикоррупционных стандартов ниже уровня, определенного федеральными законами;

- $\quad$ недопустимость объединения функций разработки, реализации и контроля над реализацией мер антикоррупционной политики;
- $\quad$ поддержания оптимального

уровня численности лиц, занимающих государственные должности и состоящих на государственной и муниципальной службе;

- целевое бюджетное финансирование мер реализации антикоррупционной политики;

- признание повышенной общественной опасности коррупционных правонарушений, совершенных лицами, занимающими должности, предусмотренные Конституцией России, Федеральными законами, Конституциями или Уставами субъектов Российской Федерации;

- недопустимость установления привилегий и иммунитетов, ограничивающих ответственность или усложняющих порядок привлечения к ответственности лиц, замещающих государственные должности, должности государственных, муниципальных и иных служащих, совершивших коррупционные правонарушения; недопустимость ограничения доступа к информации о фактах коррупции, коррупциогенных факторах и мерах по реализации антикоррупционной политики [2].

В.И. Гладких отмечает, что, планируя программу борьбы с коррупцией, необходимо исходить из следующих предпосылок. 1. Абсолютная победа над коррупцией невозможна. Более того, по мнению ряда ученых и политологов, в нормальном состоянии власти и общества коррупция является технологически полезным сигналом о неполадках в методах работы власти. 2. Ограничение коррупции не может быть разовой кампанией. За окончанием любой кампании всегда может последовать новый, более мощный виток коррупции. 3. Коррупцию нельзя ограничить только законодательными методами и борьбой с ее проявлениями. Более того, в условиях, когда коррупция достигла больших масштабов и забралась на весьма высокие уровни власти, более эффективна борьба против условий, порождающих коррупцию, чем неподготовленная атака на ее проявления. Борьба с коррупцией достигает успеха, если она всеохватна и комплексна, ведется постоянно [3] .

Из всего выше приведенного можно сделать вывод, что противодействии коррупции в сфере публичного управления должно включать в себя меры, направленные на решение следующих задач. Противодействие коррупции на всех уровнях ее проявления, сужение причин и условий, благоприятствующих коррупции, снижение, насколько это окажется возможным, выгод для обеих сторон, участвующих в коррупционных отношениях, увеличение вероятности выявления коррупционных действий и наказания за причиненный ими вред, влияния на мотивы коррупционного поведения, а также создание атмосферы 


\section{Административное и муниципальное право 11 (95) • 2015}

общественного непринятия коррупции во всех ее проявлениях [4] .

Аналогичную антикоррупционную политику проводят и ряд международных организаций. Так, Совет Европы, учитывая декларацию, принятую на второй встрече в верхах глав государств и правительств, которая состоялась в Страсбурге 10-11 октября 1997 г . и в соответствии с Планом действий, в частности разделом III, 2 «Борьба с коррупцией и организованной преступностью». Сознавая, что коррупция представляет собой серьезную опасность для основных принципов и ценностей в Совете Европы, подрывает доверие граждан к демократии, разрушает правовые нормы, представляет собой отрицание прав человека и сдерживает социально-экономическое развитие. Утвердил двадцать руководящих принципов борьбы с коррупцией [5].

Принимать эффективные меры для предотвращения коррупции и в связи с этим повышать информированность граждан и пропаганду этического поведения. Обеспечивать координацию объявления коррупции внутри страны и на международном уровне преступлением по закону. Гарантировать, что те, кто отвечает за профилактику, расследование, преследование и осуждение преступления по извлечению незаконной выгоды в противоречии с лежащими на лице должностными обязанностями и в ущерб правам других лиц, пользуются соответствующей их функциям независимостью и самостоятельностью, и располагают действиями средствами сбора доказательств, защищая тех лиц, кто помогает властям в борьбе с коррупцией, охраняя тайну следствия. Обеспечивать соответствующие мероприятия по аресту и лишению прав на доходы от преступной коррупции. Обеспечивать соответствующие мероприятия для предотвращения использования юридических лиц в качестве ширмы для преступного извлечения незаконной выгоды, противоречащей должностным обязанностям и в ущерб правам других лиц. Ограничивать освобождение (иммунитет) от расследования, преследования или осуждения за преступления, связанные с коррупцией, в той мере, в какой это необходимо в демократическом обществе. Содействовать специализации лиц и органов, ответственных за борьбу с коррупцией, и обеспечивать их соответствующими средствами и профессиональной подготовкой для исполнения ими своей работы. Гарантировать, чтобы налоговое законодательство и органы власти, отвечающие за его проведение в жизнь, действенно и скоординировано содействовали борьбе с коррупцией. Гарантировать, что в процессе принятия решений государственной администрацией учи- тывается необходимость борьбы с коррупцией, обеспечивается такая гласность, какая не вступает в противоречие с необходимостью добиваться действенности принимаемых мер. Обеспечивать, чтобы в правилах, относящимся к правам и обязанностям государственных чиновников учитывались требования борьбы с коррупцией и предусматривались соответствующие действенные дисциплинарные меры, с помощью соответствующих средств, таких как кодекс поведения, содействовать дальнейшей конкретизации такого поведения, которого ожидают от государственных чиновников. Гарантировать, чтобы к работе государственной администрации и государственному сектору применялись соответствующие процедуры ревизии. Поддерживать ту роль, которую процедуры ревизии могут сыграть в предотвращении и выявлении коррупции за пределами органов государственного управления. Обеспечивать, чтобы система государственной ответственности или ответственности по закону (подотчетность), принимала во внимание последствия бесчестного поведения государственных должностных лиц [6] .

Избирать такие гласные процедуры для государственных поставок, которые способствуют справедливой конкуренции и отпугивают лиц, намеренных извлечь незаконную выгоду путем коррупции. Рекомендовать принятие депутатам кодексов поведения и содействовать развитию таких правил финансирования политических партий и избирательных компаний, которые препятствуют проявлению коррупции. Гарантировать, чтобы средства массовой информации могли беспрепятственно получать и распространять информацию по вопросам коррупции. Гарантировать, чтобы гражданским правом принималось во внимание необходимость борьбы с коррупцией, и в частности, предусматривались эффективные средства судебной защиты тех, чьим правам и интересам нанесен ущерб в результате коррупции. Поддерживать научные исследования по коррупции. Обеспечивать, чтобы во всех аспектах борьбы с коррупцией принимались во внимание возможные связи с организованной преступностью и отмыванием денег. Максимально расширять международное сотрудничество во всех областях борьбы с коррупцией [7].

Таковы двадцать руководящих принципов Совета Европы, направленных на противодействии коррупции. В целях содействия динамичному движению к эффективному предотвращению и борьбе с коррупцией, Комитет Министров Совета Европы просит органы власти стран применять эти принципы в своих внутренних законодательствах и практике [8]. Далее представляется несколько слов сказать о том, как закреплены принципы реализа- 
ции антикоррупционных стандартов служебного поведения в некоторых государствах, в частности государствах участниках Содружества Независимых Государств.

Федеральный закон от 25 декабря 2008 г . «0 противодействии коррупции» определяет, что противодействие коррупции в Российской Федерации основывается на следующих основных принципах:

- признание, обеспечение и защита основных прав и свобод человека и гражданина;

- $\quad$ законность;

- публичность и открытость деятельности государственных органов и органов местного самоуправления;

- неотвратимость ответственности за совершение коррупционных правонарушений;

- комплексное использование политических, организационных, информационнопропагандистских, социально-экономических, правовых, специальных и иных мер;

- $\quad$ приоритетное применение мер по предупреждению коррупции;

- сотрудничество государства с институтами гражданского общества, международными организациями и физическими лицами [9].

В Законе Республики Казахстан от 2 июля 1998 г . № 267-1 «0 борьбе с коррупцией» борьба с коррупцией осуществляется на основе:

- равенства всех перед законом и судом;

- $\quad$ обеспечения четкой правовой регламентации деятельности государственных органов, законности и гласности такой деятельности, государственного и общественного контроля за ней;

- $\quad$ совершенствования структуры государственного аппарата, кадровой работы и процедуры решения вопросов, затрагивающих права и законные интересы физических и юридических лиц;

- приоритета защиты прав и законных интересов физических и юридических лиц, а также социально-экономической, политико-правовой, организационно-управленческой систем государства;

- признания допустимости ограничений прав и свобод должностных и других лиц, уполномоченных на выполнение государственных функций, а также лиц, приравненных к ним;

- $\quad$ восстановления нарушенных прав и законных интересов физических и юридических лиц, ликвидации и предупреждения вредных последствий коррупционных правонарушений;

- обеспечения личной безопасности граждан, оказывающих содействие в борьбе с коррупционными правонарушениями;

- $\quad$ защиты государством прав и законных интересов лиц, уполномоченных на выполнение госу- дарственных функций, и лиц, приравненных к ним, установления этим лицам заработной платы (денежного содержания) и льгот, обеспечивающих указанным лицам и их семьям достойный уровень жизни;

- недопустимости делегирования полномочий на государственное регулирование предпринимательской деятельности физическим и юридическим лицам, осуществляющим такую деятельность, а также на контроль за нею;

- осуществления оперативно-розыскной и иной деятельности в целях выявления, раскрытия, пресечения и предупреждения преступлений, связанных с коррупцией, а также применения в установленном законом порядке специальных мер финансового контроля в целях недопущения легализации противоправно нажитых денежных средств и иного имущества;

- установления запрета на занятие предпринимательской деятельностью, в том числе на занятие оплачиваемых должностей в органах управления хозяйствующих субъектов, за исключением случаев, когда занятие такой должности предусмотрено законодательно установленными должностными обязанностями.

Согласно Закону Республики Беларусь от 20 июля 2006 г . № 165-3 «0 борьбе с коррупцией» борьба с коррупцией основывается на принципах:

- законности;

- $\quad$ справедливости;

- $\quad$ равенства перед законом;

- гласности;

- неотвратимости ответственности;

- личной виновной ответственности;

- гуманизма.

Закон Республики Таджикистан от 25 июля 2005 г . № 100 «0 борьбе с коррупцией» определяет, что основными принципами борьбы с коррупцией являются следующие принципы, касающиеся:

- четкой правовой регламентации деятельности субъектов правонарушений, связанных с коррупцией, законности и гласности в их деятельности, государственного и общественного контроля за ними;

- совершенствования структуры государственного аппарата и процедуры решения вопросов, затрагивающих права и законные интересы физических и юридических лиц;

- признания допустимости ограничения прав и свобод лиц, уполномоченных на выполнение государственных функций, а также приравненных к ним лиц;

- установления ответственности за нарушение законодательства Республики Таджикистан о борьбе с коррупцией в соответствии с принци- 


\section{Административное и муниципальное право 11 (95) • 2015}

пами равенства всех граждан перед законом и судом;

- восстановления прав и законных интересов физических и юридических лиц, предупреждения и ликвидации вредных последствий правонарушений, связанных с коррупцией;

- защиты государством прав и законных интересов лиц, уполномоченных на выполнение государственных функций, или приравненных к ним лиц, установления заработной платы и льгот, обеспечивающих им и их семьям достойный уровень жизни;

- запрещения делегирования полномочий по государственному регулированию и контролю за предпринимательской деятельностью физическим и юридическим лицам, осуществляющим такую деятельность;

- проведения оперативно-розыскной деятельности в целях предупреждения, выявления, раскрытия и пресечения преступлений коррупционного характера, а также специальных мер финансового контроля;

- обеспечения личной безопасности граждан, оказывающих содействие в борьбе с правонарушениями, связанными с коррупцией.

В завершении подчеркнем, что проблемы предупреждения и пресечения коррупции в органах государственной власти и управления требуют системного подхода. Уровень развития коррупции, степень ее общественной опасности, а также разнообразные формы ее проявления, требуют адекватных мер реагирования всех государственных институтов и структур. Кроме того, как уже неоднократно подчеркивалось борьба с коррупцией может дать определенные позитивные результаты только при участии в соответствующих антикоррупционных мероприятиях большинства институтов гражданского общества России.

В завершении рассмотрения обозначенного вопроса отменим, что принципы играют важную роль в деле противодействия коррупции в системе государственной службы. Следует также отметить, что принципы реализации ан тикоррупционных стандартов служебного поведения государственных гражданских служащих делают соответствующую деятельность более целенаправленной, а также позволяют концентрировать имеющиеся средства и ресурсы на тех аспектах служебной деятельности служащих, которые в наибольшей степени подвержены коррупционному воздействию [10] .

Традиционно принципы, какой-либо деятельности дифференцируются по определенным основаниям или критериям, позволяющим увидеть в них общее и особенное. Рассматриваемые принципы исключением не является, так принципы реализации ан тикоррупционных стандартов служебного поведения государственных гражданских служащих подразделяются на общие принципы, специальные и организационные. Говоря об общих принципах реализации рассматриваемых стандартов, то здесь традиционно выделяется принцип законности, обоснованности, справедливости, равенства перед законом и др.

Специальные принципы определяют специфические аспекты в реализации антикоррупционных стандартов служебного поведения, в частности к таким принципам относится принцип профессиональной служебной этики, принцип обязательности соблюдения запретов и ограничений, обусловленных режимом государственной службы, принцип лояльности, принцип неотвратимости и адекватности юридической ответственности за коррупционные правонарушения. В исследовании прослеживается определенная логическая цепочка взаимосвязанности принципов государственной службы, принципов противодействия коррупции, а также принципов реализации ан тикоррупционных стандартов служебного поведения государственных гражданских служащих. Такая связь вполне естественна, поскольку все эти принципы имеют по сути административно-правовую природу, в этой связи соблюдение принципов одной группы одновременно влечет за собой и соблюдение принципов касающихся правового регулирования смежных государственно-служебных отношений [10] .

Говоря об организационных принципах реализации ан тикоррупционных стандартов служебного поведения государственных гражданских служащих, то они в меньшей степени находят свое нормативное закрепление, а между тем это самые динамические принципы, учет которых влияет на итоговый результат всей деятельности по противодействию коррупции в системе государственной службы. Изучение действующего законодательства, а также ряда программных документов посвященных проблеме противодействия коррупции позволяет сделать вывод о том, что одна из приоритетных задач антикоррупционной политики является профилактика коррупции, а также создание атмосферы не терпимости к различным должностным - корыстным злоупотреблениям как в обществе в целом, так и в корпоративной чиновничьей среде.

Для решения этой задачи предполагается проведение различного рода просветительских мероприятий антикоррупционного содержание, создание подразделений в органах власти и управления по профилактики коррупции, по разрешению конфликта интересов и обеспечения надлежащего служебного поведения, а также 
проведения иных организационных мероприятий по соответствующему предмету. К сожалению, приходиться констатировать многие из нормативно закрепленных организационных мероприятий, которые должны были быть направлены на противодействие и профилактику коррупции должным образом не выполняются. Формально сформированные комиссии по разрешению конфликта интересов и обеспечения надлежащего служебного поведения в большинстве федеральных органов исполнительной власти с момента своего создания не провели ни одного заседания.

Все эти, а также ряд иных фактов могут красноречиво свидетельствовать о том, что организационный механизм противодействия коррупции, в целом, а также при реализации ан тикоррупционных стандартов служебного поведения государственных гражданских служащих, в частно- сти не работает. В этой связи уже сейчас, несмотря на то, что с момента принятия основных нормативных документов по вопросу противодействия коррупции прошло чуть менее пяти лет необходимо провести ревизию в соответствующем массиве нормативных правовых актов, принятых по предмету противодействия коррупции. Нужно выявить какие предписания, содержащиеся в них, не используются, а также установить причины подобного положения вещей. Учитывая сложившееся положение дел в рассматриваемой сфере было бы вполне целесообразно установить меры административной ответственности должностных лиц в виде дисквалификации за бездействия в реализации законодательства о противодействии коррупции и обеспечения ан тикоррупционных стандартов служебного поведения государственных гражданских служащих.

\section{Библиография:}

1. Зажицкий В.И. Правовые принципы в законодательстве Российской Федерации // Государство и право. - 1996. № 11. - С. 92.

2. Лопатин В.Н. О системном подходе в антикоррупционной политики // Государство и право. - 2001. - № 7. - С. 27.

3. Гладких В.И. Коррупция в России: генезис, детерминанты и пути преодоления // Российский следователь. 2001. - № 3. - С. 35.

4. Кузнецов А.Н. Преодоление коррупции в государственном аппарате (теоретико-правовой аспект): Дис. ... канд. юрид. наук.- СПб., 2000. - С. 156.

5. Приложение III. Резолюция о 20 руководящих принципах в борьбе с коррупцией (принята комитетом министров 6 ноября 1997 г . на его 101-й встрече).

6. Куракин А.В. Административно-правовое регулирование принципов государственной гражданской службы Российской Федерации // Административное и муниципальное право. - 2009. - № 3. - С.12.

7. Куракин А.В. Предмет административно-правового регулирования в механизме противодействия коррупции в полиции. - Домодедово, 2013. - С. 46.

8. Reif C. Building Democratic Institutions: The Role of National Human Rights Institutions in Good Governance and Human Rights Protection // Howard Human Rights Journal. 2000. Vol.

9. Куракин А.В. Административно-правовое регулирование принципов государственной гражданской службы Российской Федерации // Административное и муниципальное право. - 2009. - № 3. - С.12.

10. Куракин А.В. Административно-правовое регулирование принципов государственной гражданской службы Российской Федерации // Административное и муниципальное право. - 2009. - № 3. - С.12.

11. Лаврентьева 0.0. Контроль в системе государственной службы как средство противодействия коррупции // NB: Административное право и практика администрирования. - 2014. - 4. - C. 51 - 73. DOI: 10.7256/23069945.2014.4.12224. URL: http://www.e-notabene.ru/al/article_12224.html

12. Куракин А.В. Административно-правовые аспекты юридической ответственности в механизме противодействия коррупции в системе государственной службы Российской Федерации // NB: Административное право и практика администрирования. - 2013. - 7. - C. 137 - 157. DOI: 10.7256/2306-9945.2013.7.9954. URL: http://www.enotabene.ru/al/article_9954.html

13. Лаврентьева 0.0. Антикоррупционный контроль в системе государственной службы // Административное и муниципальное право. - 2012. - 12. - С. 35 - 43.

14. Куракин А.В. Международное и административное право и противодействие коррупции в системе государственной гражданской службы // NB: Административное право и практика администрирования. - 2014. - 1. - C. 53 - 81. DOI: 10.7256/2306-9945.2014.1.11051. URL: http://www.e-notabene.ru/al/article_11051.html

15. Лаврентьева 0.0. Административно-правовые меры минимизации коррупционных рисков в системе государственной гражданской службы и принципы их реализации // Административное и муниципальное право. 2014. - 5. - C. 469 - 477. DOI: 10.7256/1999-2807.2014.5.11934.

16. Куракин А.В., Костенников М.В. Административно-правовое противодействие коррупции в системе государственной службы и в деятельности сотрудников полиции Российской Федерации и зарубежных государств // Полицейская и следственная деятельность. - 2013. - 1. - С. 65 - 83. DOI: 10.7256/2409-7810.2013.1.735. URL: http://www.e-notabene.ru/pm/article_735.html

17. Куракин А.В., Лаврентьева О.О. Принципы государственной гражданской службы в механизме противодействия коррупции // Административное и муниципальное право. - 2012. - 9. - С. 15 - 24. 


\section{Административное и муниципальное право 11 (95) • 2015}

18. Куракин А.В., Костенников М.В. Новая книга о государственной гражданской службе Рецензия на учебный курс А.А. Гришковца по теме: «Государственная гражданская служба». - М.: Дело и Сервис, 2014. - 624 с. // Административное и муниципальное право. - 2014. - 3. - С. 294 - 298. DOI: 10.7256/1999-2807.2014.3.11252.

19. Костенников М.В., Куракин А.В., Кошелев И.Н. Административно-правовое регулирование обеспечения собственной безопасности и противодействия коррупции в органах внутренних дел (ч. 3 окончание начало в № 1 , 2 - 2011 г.) // Административное и муниципальное право. - 2011. - 4. - С. 52 - 61.

20. Куракин А.В., Остроушко А.В. Рецензия на монографию Букалеровой Л.А., Гаврюшкина Ю.Б. «Компаративный анализ уголовно-правового противодействия посредничеству во взяточничестве». - М.: «Юрлитинформ», 2014. - 192 с. // Административное и муниципальное право. - 2014. - 10. - C. 1081 - 1084. DOI: 10.7256/19992807.2014.10.13056.

\section{References (transliterated):}

1. Zazhitskii V.I. Pravovye printsipy v zakonodatel'stve Rossiiskoi Federatsii // Gosudarstvo i pravo. - 1996. - № 11. - S. 92.

2. Lopatin V.N. O cictemnom podkhode v antikorruptsionnoi politiki // Gosudarstvo i pravo. - 2001. - № 7. - S. 27.

3. Gladkikh V.I. Korruptsiya v Rossii: genezis, determinanty i puti preodoleniya // Rossiiskii sledovatel'. - 2001. - № 3. S. 35 .

4. Kuznetsov A.N. Ppeodolenie korruptsii v gosudarstvennom apparate (teoretiko-pravovoi aspekt): Dis. ... kand. yurid. nauk.- SPb., 2000. - S. 156.

5. Ppilozhenie III. Rezolyutsiya o 20 rukovodyashchikh printsipakh v bor'be s korruptsiei (prinyata komitetom ministrov 6 noyabrya $1997 \mathrm{~g}$. na ego 101-i vctpeche).

6. Kurakin A.V. Administrativno-pravovoe regulirovanie printsipov gosudarstvennoi grazhdanskoi sluzhby Rossiiskoi Federatsii // Administrativnoe i munitsipal'noe pravo. - 2009. - № 3. - S.12.

7. Kurakin A.V. Predmet administrativno-pravovogo regulirovaniya v mekhanizme protivodeistviya korruptsii v politsii. Domodedovo, 2013. - S. 46.

8. Reif C. Building Democratic Institutions: The Role of National Human Rights Institutions in Good Governance and Human Rights Protection // Howard Human Rights Journal. 2000. Vol.

9. Kurakin A.V. Administrativno-pravovoe regulirovanie printsipov gosudarstvennoi grazhdanskoi sluzhby Rossiiskoi Federatsii // Administrativnoe i munitsipal'noe pravo. - 2009. - № 3. - S.12.

10. Kurakin A.V. Administrativno-pravovoe regulirovanie printsipov gosudarstvennoi grazhdanskoi sluzhby Rossiiskoi Federatsii // Administrativnoe i munitsipal'noe pravo. - 2009. - № 3. - S.12.

11. Lavrent'eva 0.0. Kontrol' v sisteme gosudarstvennoi sluzhby kak sredstvo protivodeistviya korruptsii // NB: Administrativnoe pravo i praktika administrirovaniya. - 2014. - 4. - C. 51 - 73. DOI: 10.7256/2306-9945.2014.4.12224. URL: http://www.e-notabene.ru/al/article_12224.html

12. Kurakin A.V. Administrativno-pravovye aspekty yuridicheskoi otvetstvennosti v mekhanizme protivodeistviya korruptsii v sisteme gosudarstvennoi sluzhby Rossiiskoi Federatsii // NB: Administrativnoe pravo i praktika administrirovaniya. 2013. - 7. - C. 137 - 157. DOI: 10.7256/2306-9945.2013.7.9954. URL: http://www.e-notabene.ru/al/article_9954.html

13. Lavrent'eva 0.0. Antikorruptsionnyi kontrol' v sisteme gosudarstvennoi sluzhby // Administrativnoe i munitsipal'noe pravo. - 2012. - 12. - C. $35-43$.

14. Kurakin A.V. Mezhdunapodnoe i administrativnoe pravo i protivodeistvie korruptsii v sisteme gocudapctvennoi grazhdanskoi sluzhby // NB: Administrativnoe pravo i praktika administrirovaniya. - 2014. - 1. - C. 53 - 81 . DOI: 10.7256/2306-9945.2014.1.11051. URL: http://www.e-notabene.ru/al/article_11051.html

15. Lavrent'eva 0.0. Administrativno-pravovye mery minimizatsii korruptsionnykh riskov v sisteme gosudarstvennoi grazhdanskoi sluzhby i printsipy ikh realizatsii // Administrativnoe i munitsipal'noe pravo. - 2014. - 5. - C. 469 - 477. DOI: 10.7256/1999-2807.2014.5.11934.

16. Kurakin A.V., Kostennikov M.V. Administrativno-pravovoe protivodeistvie korruptsii v sisteme gosudarstvennoi sluzhby i v deyatel'nosti sotrudnikov politsii Rossiiskoi Federatsii i zarubezhnykh gosudarstv // Politseiskaya i sledstvennaya deyatel'nost'. - 2013. - 1. - C. 65 - 83. DOI: 10.7256/2409-7810.2013.1.735. URL: http://www.e-notabene.ru/pm/ article_735.html

17. Kurakin A.V., Lavrent'eva O.0. Printsipy gosudarstvennoi grazhdanskoi sluzhby v mekhanizme protivodeistviya korruptsii // Administrativnoe i munitsipal'noe pravo. - 2012. - 9. - C. 15 - 24.

18. Kurakin A.V., Kostennikov M.V. Novaya kniga o gosudarstvennoi grazhdanskoi sluzhbe Retsenziya na uchebnyi kurs A.A. Grishkovtsa po teme: «Gosudarstvennaya grazhdanskaya sluzhba». - M.: Delo i Servis, 2014. - 624 s. // Administrativnoe i munitsipal'noe pravo. - 2014. - 3. - C. 294 - 298. DOI: 10.7256/1999-2807.2014.3.11252.

19. Kostennikov M.V., Kurakin A.V., Koshelev I.N. Administrativno-pravovoe regulirovanie obespecheniya sobstvennoi bezopasnosti i protivodeistviya korruptsii v organakh vnutrennikh del (ch. 3 okonchanie nachalo v № 1,2 - 2011 g.) // Administrativnoe i munitsipal'noe pravo. - 2011. - 4. - C. 52 - 61.

20. Kurakin A.V., Ostroushko A.V. Retsenziya na monografiyu Bukalerovoi L.A., Gavryushkina Yu.B. «Komparativnyi analiz ugolovno-pravovogo protivodeistviya posrednichestvu vo vzyatochnichestve». - M.: «Yurlitinform», 2014. - 192 s. // Administrativnoe i munitsipal'noe pravo. - 2014. - 10. - C. 1081 - 1084. DOI: 10.7256/1999-2807.2014.10.13056. 